Preprint. Final version appears as:

Bull, P. \& Morgan, R. (2006) Sediment Fingerprints: A forensic technique using quartz sand grains. Science and Justice, Vol 46, pp. 46-107

Sediment Fingerprints: A forensic technique using quartz sand grains

Bull, P. and Morgan, R.

Communicating author: Ruth Morgan

Ruth.morgan@ucl.ac.uk

Tel: +44 2031083037

Fax: +442031083088 


\title{
Sediment Fingerprints: A forensic technique using quartz sand grains
}

\author{
PA Bull* and RM Morgan \\ Oxford University Centre for the Environment, University of Oxford, OX13QY \\ peter.bull@hertford.ox.ac.uk \\ Science \& Justice 200646107 - 124 Received 10 March 2005 accepted 10 October 2005
}

\begin{abstract}
The analyses of 738 soil and sediment samples taken during the investigation of 20 forensic cases are combined in a database for retrospective comparisons. Quartz sand grain surface textures are combined into grain types which are analysed at one of five orders of classification. This classification also provides frequency data on the number of grain types found in a sample, the individuality of the quartz grain type assemblages and quartz grain type ratios. The technique, developed primarily as an exclusion mechanism, suggests possibilities, in some circumstances, that significant interpretations can be achieved at different orders of classification. The technique provides excellent exclusionary results and, when combined with other independent lines of analysis, is a powerful tool in forensic interpretation because it uses quartz as its discriminatory mineral. The technique also highlights the potential for computer image recognition analysis.
\end{abstract}

Se combinan en una base de datos, con fines de comparación retrospectiva, los análisis de 738 muestras de suelo y sedimentos tomados en la investigación de 20 casos forenses. Las texturas de superficies de arena con granos de cuarzo se combinan en tipos de grano que son analizadas como una de cinco órdenes de clasificación. Esta clasificación también provee datos de frecuencia de los tipos de grano encontrados en una muestra, la individualidad de ensamblajes de los tipos de grano de cuarzo y los cocientes de los tipos de grano de cuarzo. La técnica, desarrollada en un principio como un mecanismo de exclusión, sugiere posibilidades en algunas circunstancias de que se pueden conseguir interpretaciones significativas en distintos órdenes de clasificación. La técnica provee resultados de exclusión excelentes y , cuando se combina con otras líneas independientes de análisis es una herramienta poderosa en interpretación forense ya que utiliza el cuarzo como mineral discriminatorio. La técnica también ensalza el potencial del análisis mediante imagen computerizada.
Die während der Untersuchung von 20 Fällen gewonne nen Analysenergebnisse an 738 Boden- und Sedimentproben wurden für retrospektive Vergleiche in einer Datenbank zusammengefasst. Die Oberflächenstrukturen von Quarzsandkörnern wurden zu Korntypen zusammengefasst, die bezüglich eines von fünf Klassifizierung sgraden analysiert wurden. Diese Klassifizierung liefert auch Informationen über die Anzahl der Korntypen in einer Probe und die Individualität der Zusammenstellung und der jeweiligen Mengenverhältnisse von Quartzkorntypen. Diese primär als Ausschlussproze dur entwickelte Methode eröffnet unter bestimmten Rahmenbedingungen die Möglichkeit, auf verschiedenen Ebenen der Klassifizierung signifikante Schlussfolgerungen zu ziehen. Mit dieser Methode sind exzellente Ausschlussresultate zu erzielen und in Verbindung mit anderen, unabhängigen Untersuchungslinien ist sie ein leistungsfähiges forensisches Werkzeug, da Quartz als diskriminierendes Mineral eingesetzt wird. Die Methode hebt auch das Potenzial der computergestützen Bilderkennung und -analyse hervor.

L'analyse de 738 échantillons de terre et de sédiment pris durant l'investigation de 20 cas forensiques sont combinés dans une banque de données pour des comparaisons rétrospectives. Les textures de surface des grains de sable de quartz sont combinées en types de grains, qui sont analysés parmi cinq ordres de classification. Cette classification procure des données de fréquence sur le nombre de type de grains trouvé dans un échantillon, l'individualité des assemblages de type de grains de quartz et les rapports de types de grains de quartz. La technique, développée principalement à des fins d'exclusion, suggère les possibilités, dans certaines circonstances, de pouvoir procéder à des interprétations significatives de différents ordres de classification. La technique procure des résultats d'exclusion excellents, et lorsqu'elle est combinée avec d'autres directions d'analyses, est un outil puissant dans l'interprétation forensique parce qu'elle utilise le quartz comme minerai discriminant. La technique met en exergue également le potentiel de l'analyse de reconnaissance par l'image numérique.

*Author for correspondence

(c) The Forensic Science Society 2006

Key words Forensic science, sediment and soils, quartz surface textures, quartz grain types, quartz grain assemblages, scanning electron microscopy, database. 


\section{Introduction}

Quartz is easily the most common mineral on the Earth [1]. It is particularly resistant to mechanical breakdown during the erosion of rocks and the subsequent movement of sediment in water, wind or gravity. This resistance is enhanced by the ability of quartz to resist chemical attack by atmospheric agents, soil acids and percolating waters. Its comparative resilience in the natural world means that it is often the mineral that is left behind after everything else has been either eroded or dissolved away; hence its abundance on the beach in the form of sand grains. It is not surprising therefore, that quartz makes up the substantial content of many soils and as such is potentially a very important mineral in forensic analysis.

The very resistant nature of quartz enables it to be used to reconstruct the various agencies that have acted upon the sand grain in both its recent past and in its more distant geological past. It has been possible to reconstruct the history of a sand grain back over 600 million years [2] although most geological studies concentrate on the last million or so years [3]. It is, however, possible to reconstruct the journey that a sand grain took only days, weeks or years ago. The geological and forensic history of a quartz sand grain idealised in Figure 1, shows the various cycles of erosion that a grain can be subjected to. Each of these geological events can impart modification textures to a quartz sand grain and, as will be seen later, the addition of modern day anthropogenic materials can alter the assemblage characteristics of a sediment.

The three things that affect the physical appearance of a quartz sand grain are:

1. the origin of the grain and how it was removed from its parent rock;

2. the transportation mechanism of the grain away from the parent rock to where it now lies;

3. the history of the grain subsequent to deposition in the soil or other sediment where it now rests.

This paper will show that the very complex nature of the history of a sand grain enables the surface textures found on the quartz grains to be used as a very powerful descriptive tool for comparison between sites. Furthermore, it will be shown that sediments or soils have been transported during the geological past in very coherent sediment bodies with only discrete mixing of materials. This results in very distinctive assemblages of quartz grain types being found in any particular location, further enhancing the comparison ability of quartz grain analysis for forensic investigation. The alteration of soils and sediments by human interference further increases the potential capabilities of

Table 1 Quartz grain surface textures used to identify grain types

\begin{tabular}{lll}
\hline \multicolumn{1}{c}{ Mechanical Features } & \multicolumn{1}{c}{ Chemical Features } & Morphological Features \\
\hline Complete grain breakage & Oriented etch pits & Rounded \\
Upturned plates & Anastomosis & Subrounded \\
Hertzian fractures & Dulled surface & Subangular \\
Blocky edge abrasion & Solution pits & Angular \\
Platey edge abrasion & Solution crevasses & Low relief \\
Breakage blocks & Surface scaling & Medium relief \\
Conchoidal fractures & Carapace & High relief \\
Stepping & Amorphous precipitation & Elongate grains \\
Grinding features & Euhedral overgrowths & Irregular shape grains \\
Adhering particles & Diagenetic smoothing & Polycrystalline form \\
Fracture plates & Chattermarks & Microcrystalline form \\
Meandering ridges & Edge rounding & \\
Mechanical scratches & Silica gel globules & \\
V pits (indentors) & Biological etching & \\
Star fractures & & \\
Dish-shaped concavities & &
\end{tabular}


Figure 1 Idealised geological and geomorphological chronology of events through which a quartz sand grain can pass prior to forensic analysis.

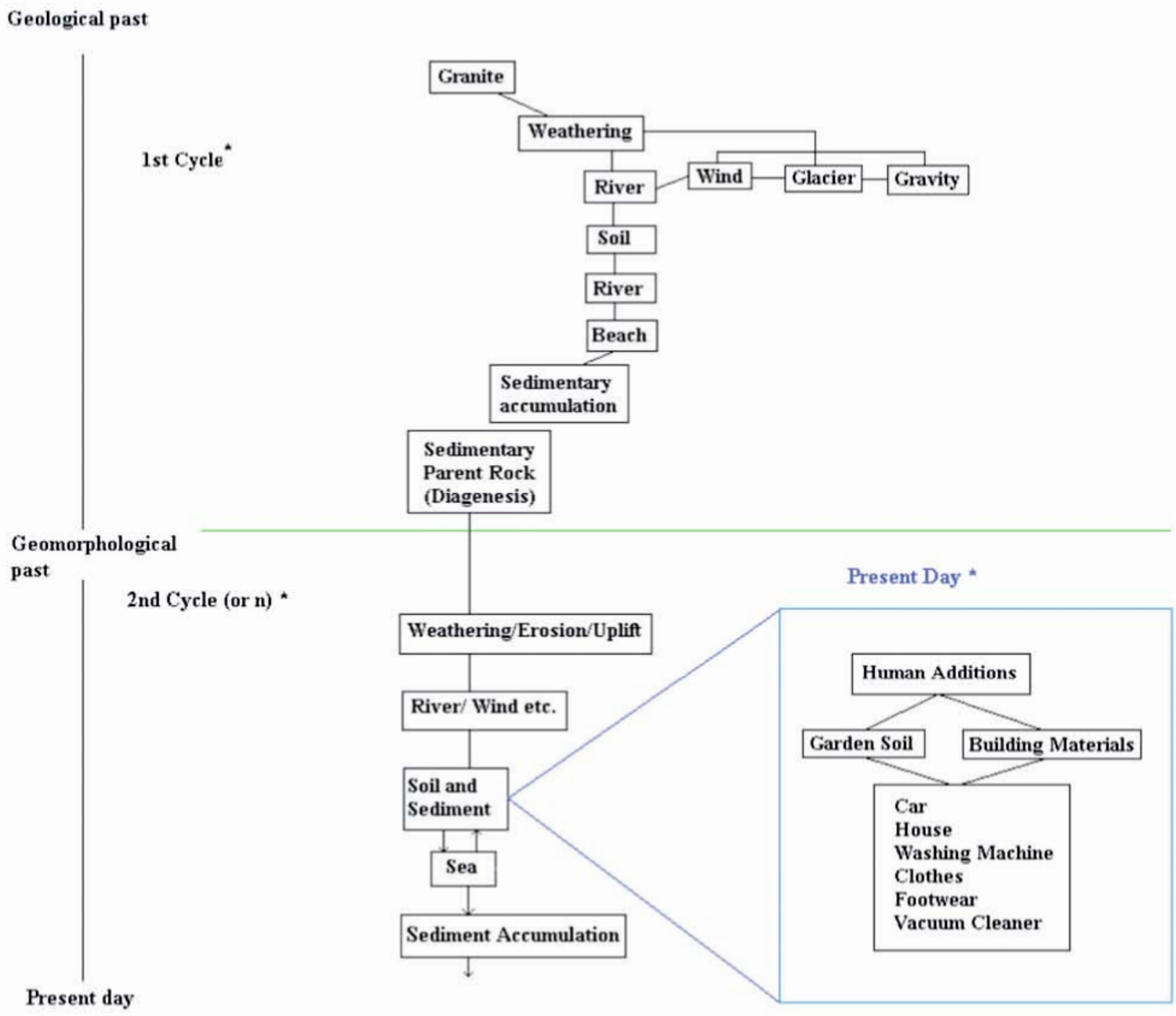

*Any point is a potential provenance site for forensic material

quartz grain studies. The introduction of exotic soils through agriculture (or even gardening) and the presence of sands used specifically for cements, building, grouting, pavier blocks, engineering, or sand blasting, enables unusual grains to be introduced into local soils providing extremely powerful comparison grains in forensic analysis and adding to the distinguishing power of the technique.

The results provided in this paper represent an amalgam of studies undertaken whilst analysing sediments associated with a number of criminal cases brought in Britain over the last twelve years. They complement geological studies using the same techniques undertaken over the last thirty years. Quartz sand grain analysis of these samples undertaken by scanning electron microscopy (SEM) has often been employed in conjunction with other soil and sediment studies using various geological, botanical and chemical analyses.

\section{Background rationale}

\section{Soils and sediments}

Soils and sediments form the loose skin lying upon consolidated rocks which constitute the building blocks of the landscape. The sediments can range in thickness from a few millimetres on the crests and upper flanks of hills, to tens, or even hundreds of metres depth in the valley bottoms occupied by large rivers.

Soils are, by definition, richer in organic material than sediments, but both types of materials owe their origin to one of two mechanisms; they are either products of weathering of the underlying rock, or are deposits brought into the area by a 
Figure 2 SEM micrograph of conchoidal fractures on a quartz sand grain. Scale bar 20 microns.

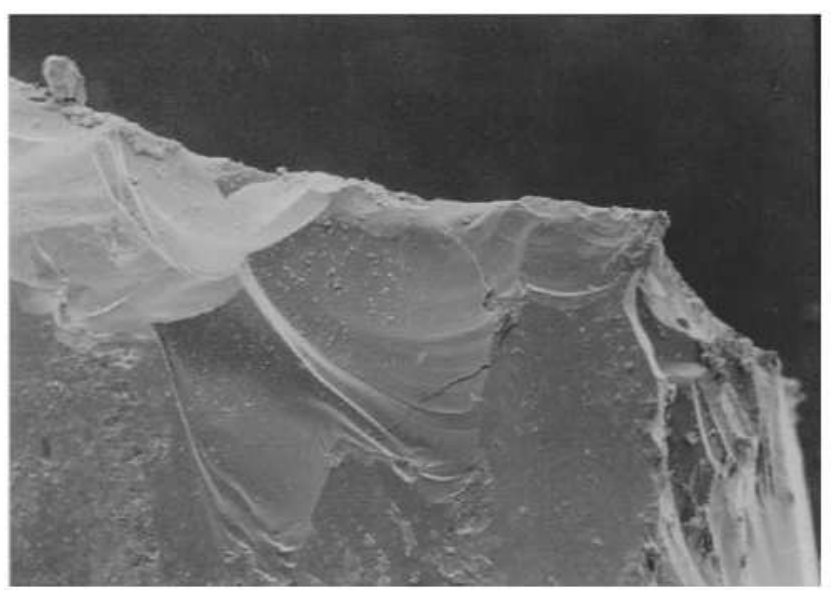

Figure 4 SEM micrograph of quartz sand grain exhibiting impact features caused during river transportation. Scale bar 10 microns.

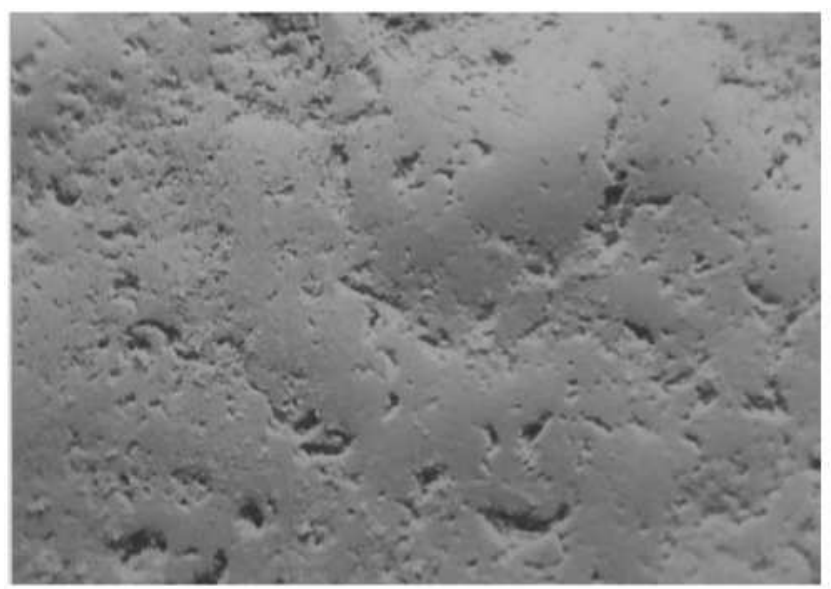

Figure 6 SEM micrograph of quartz sand grain exhibiting impact features caused during wind transportation. Scale bar 10 microns.

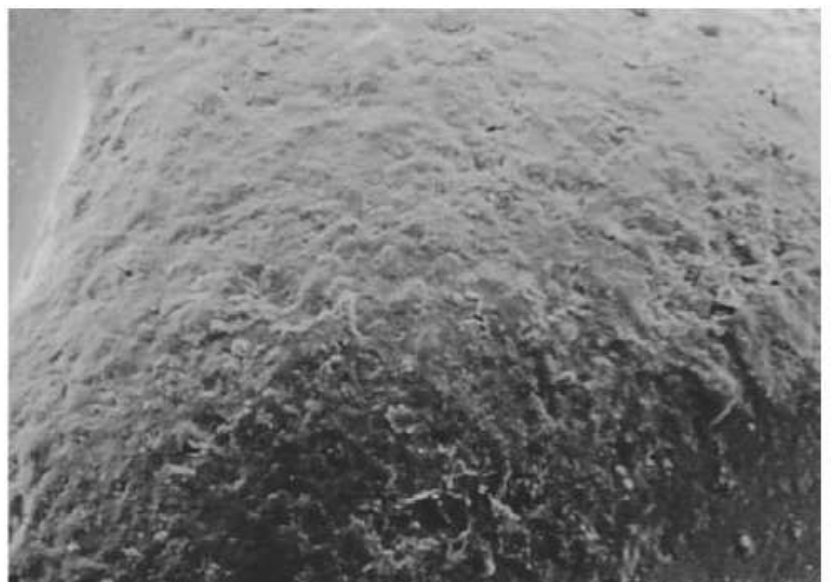

Figure 3 SEM micrograph of quartz sand grain exhibiting blocky breakage. Scale bar 20 microns.

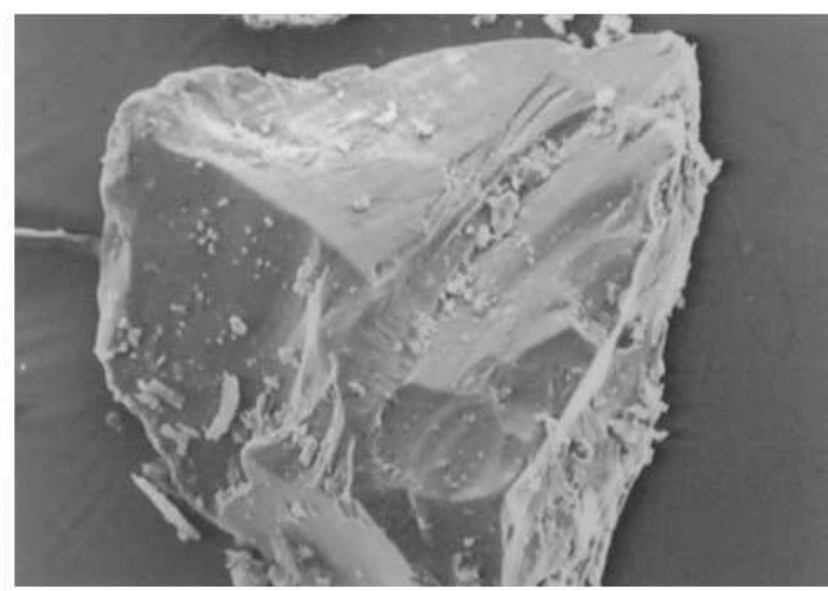

Figure 5 SEM micrograph of quartz sand grain exhibiting impact features caused during transportation in a beach zone. Scale bar 20 microns.

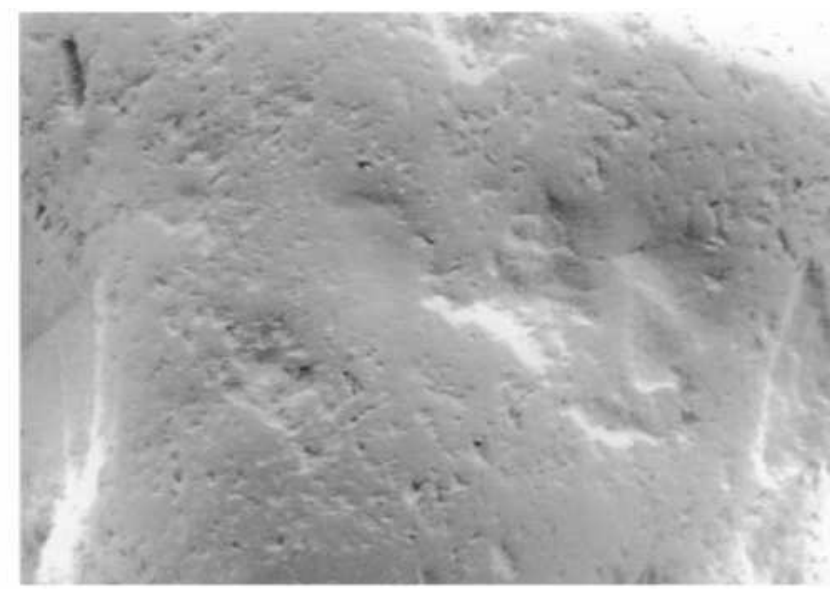

Figure 7 SEM micrograph of quartz sand grain exhibiting complete grain breakage. Scale bar 30 microns.

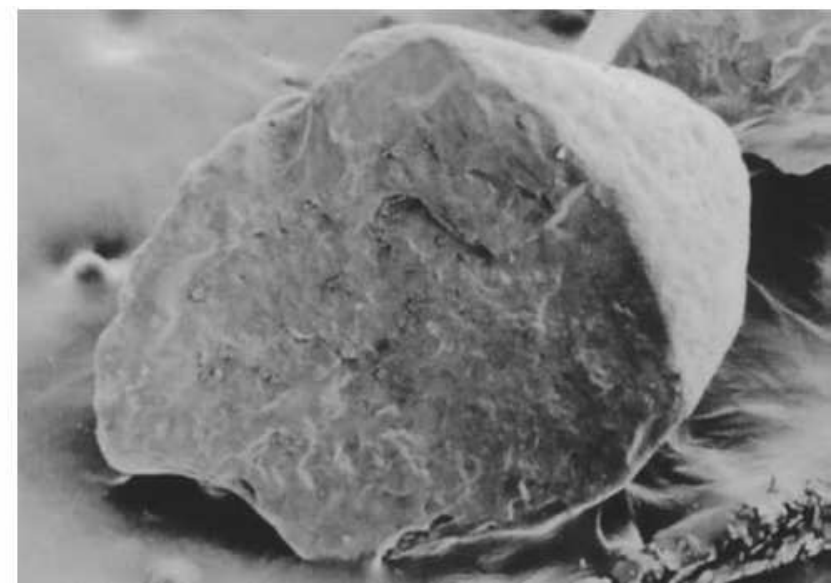


Figure 8 SEM micrograph of quartz sand grain exhibiting platy edge abrasion. Scale bar 40 microns.

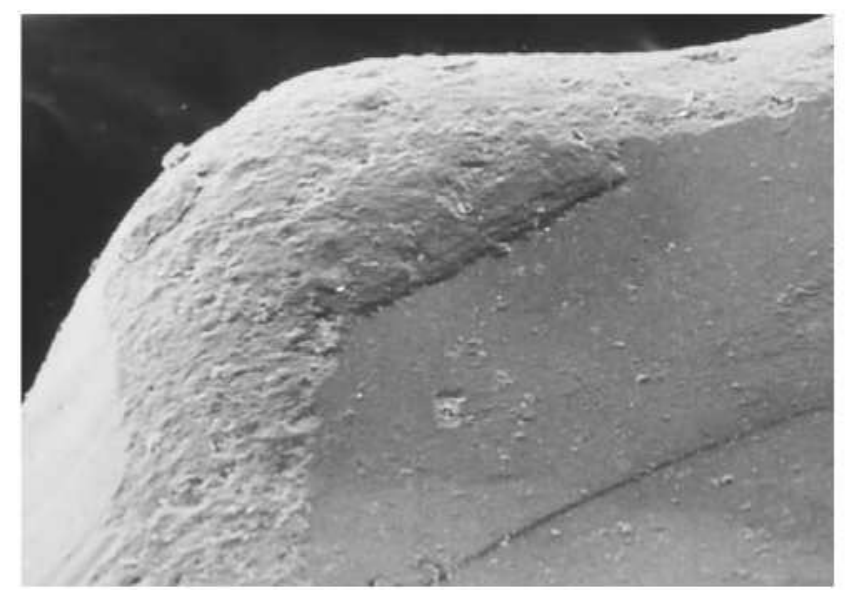

Figure 10 SEM micrograph of quartz sand grain exhibiting crescentic Hertzian fractures. Scale bar 20 microns.

Figure 11 SEM micrograph of quartz sand grain exhibiting

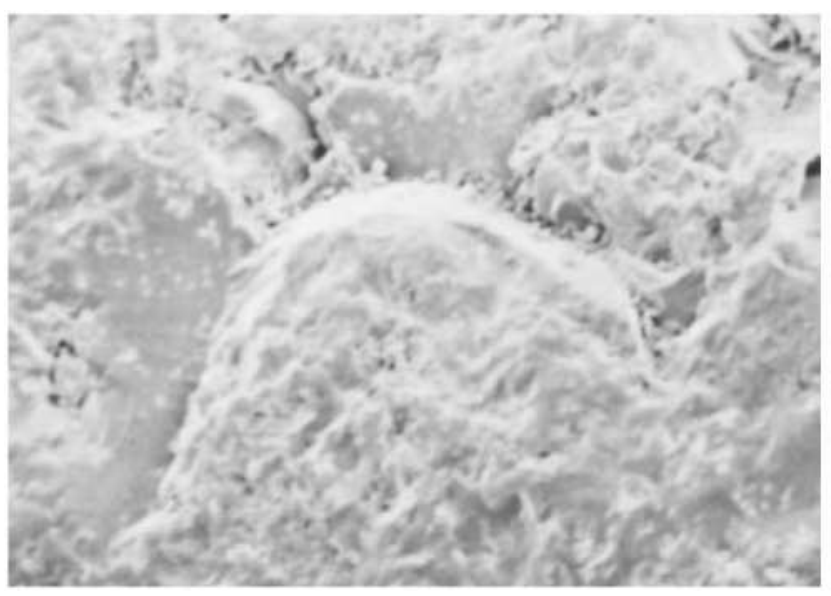

Figure 12 SEM micrograph of quartz sand grain exhibiting glacial grinding and crushing with subsequent edge rounding. Scale bar 20 microns.

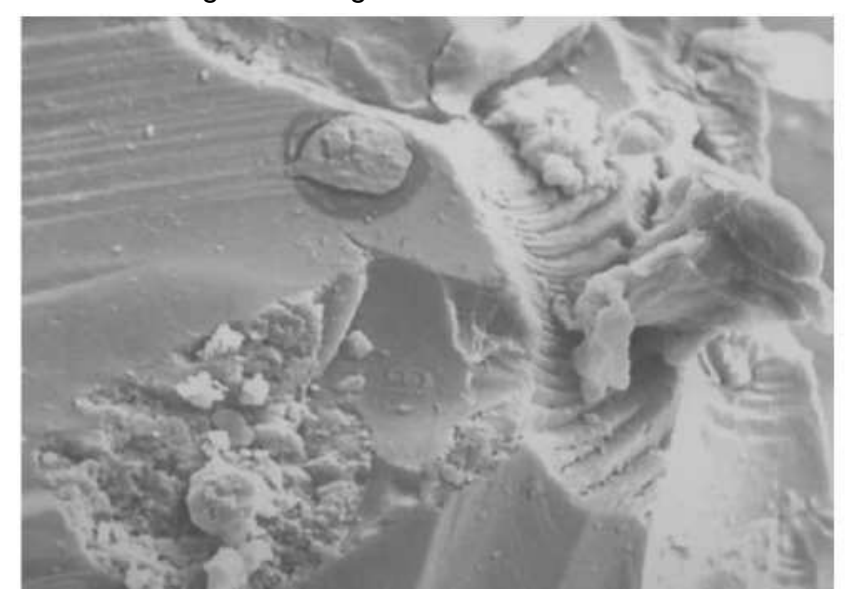

Figure 9 SEM micrograph of quartz sand grain exhibiting blocky edge abrasion. Scale bar 40 microns.

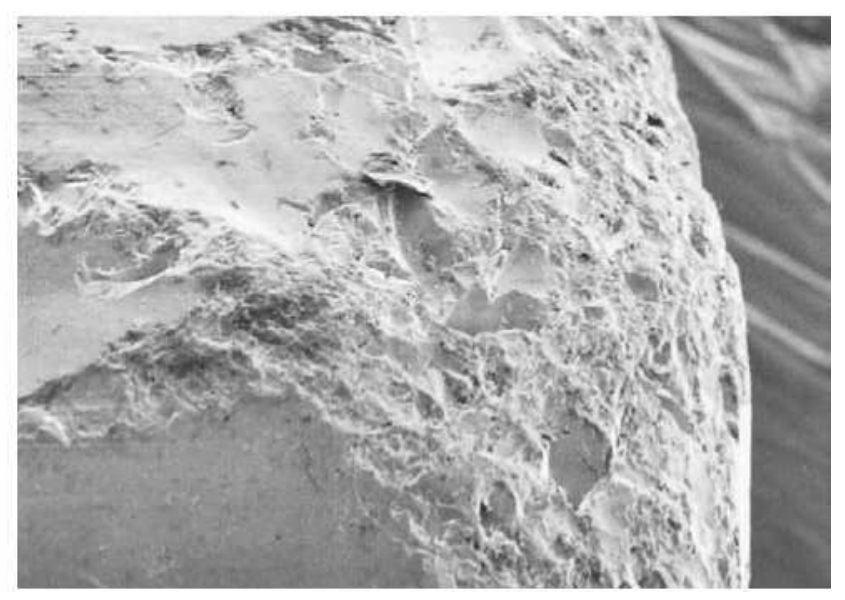

star fractures (centre left). Scale bar 20 microns.

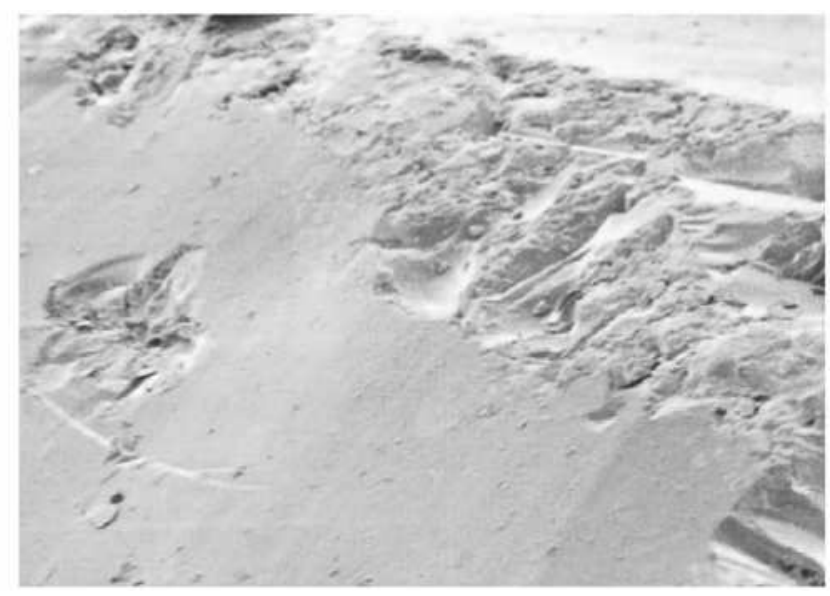

Figure 13 SEM micrograph of quartz sand grain exhibiting selective grain solution. Scale bar 20 microns.

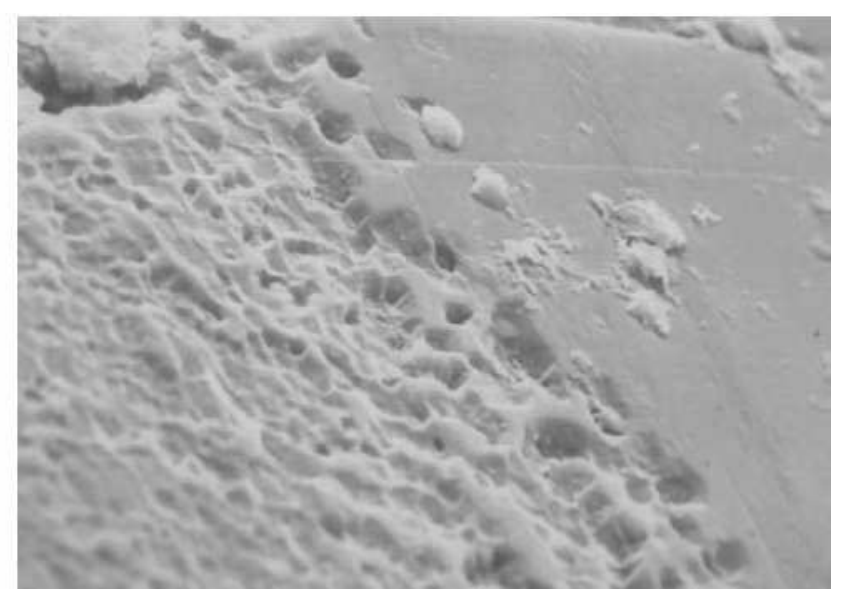


number of agencies. These agencies include ancient and modern processes such as glaciation, rivers, wind, gravity, the sea and in more recent times, human introductions such as landfill, madeground and building activity.

The grain size of soils and sediments vary considerably. In the majority of forensic cases, sand, silt and clay-sized material predominate and of these, the sand-sized materials are the most ideal for quartz grain surface texture analysis. Silt and clay sized quartz grains can also yield positive results for forensic analysis but must be interpreted with great care.

\section{Quartz grain surface textures}

The ability of a quartz sand grain to resist both mechanical abrasion and chemical solution results in it surviving erosion, transportation and alteration during deposition. Each of the phases of this cycle of erosion can however, result in modification to the grain surface and indeed, by the use of high power scanning electron microscopy, specific surface textures can be found which typify the characteristic energy conditions found in different environments. Table 1 summarizes the most common textures found on quartz sand grains.

Since quartz has no apparent cleavage, it breaks in a characteristic fracture [4]. These fractures can take the form of spoon-shaped, conchoidal breakage but can also be more blocky in form. This latter shape owes much to the microfracturing inherent in the host quartz-rich rock which develops when the quartz cools from its molten state into its solid state in a granite [4]. This breakage pattern will remain with the grain even if it is subsequently incorporated into a sandstone during a sedimentary cycle. Later breakage during transportation may well be controlled by these inherent weaknesses set within the quartz crystal. Thus, conchoidal fractures and breakage blocks (Figures 2 and 3) are common on quartz grain surfaces that have undergone compression and subsequent failure. Perhaps the most dynamic environment which exhibits this energy condition is the glacial environment and since Britain has undergone a number of severe glaciations during the recent geological past [5], it is not surprising that such textures are found in many areas of Britain.

By far the most distinctive modification features found on a quartz grain surface is the impact feature. Such features can be the result of grain-to-grain collision as found in turbulent rivers, in the wave zone of a beach, or through aeolian transportation (Figures 4, 5 and 6). Alternatively, a collision can be between a grain and an immovable object. Here the energy of impact is fully absorbed by the sand grain often resulting in complete grain breakage (Figure 7).

Quartz grains transported and modified in subaqueous (river or sea) environments exhibit surface textures indicative of collision between grains. The resultant shape of these impact features will depend upon the force of collision of those grains and upon the shape of the impacting grains. Abrasion of sharp grain edges is the most obvious indication of grain movement in subaqueous environments; indeed, even gentle soil creep caused by rainwash on a slope can impart edge abrasion

(Figures 8 and 9). Other impact features found in subaqueous environments include individual 'chips' which often take the form of v-shaped pits or indentors that can be found located across the grain surface. In certain circumstances, crescentshaped (hertzian) or star-shaped fractures can form (Figures 10 and 11). Often these subaqueous textures can be found superimposed upon other features showing, for example, glacial textures with subsequent subaqueous modification indicative of the melting of a glacier (Figure 12). Thus, a detailed reconstruction of the history of a quartz sand grain can be achieved, enabling grain classification to be made with confidence.

The transportation of quartz sand grains in the wind can result in grain collisions which impart platy textures across the whole grain surface (Figure 6). These features are very indicative of modification during transportation in mature aeolian sand seas and can be found in association with very well rounded and low relief grains.

Following deposition, sediments develop into soils by the natural introduction of organic debris and vegetation. This process of pedogenesis increases the amount of acids or bases in the infiltrating waters and in turn, can affect the surface of the quartz sand grains causing either solution or deposition onto the surface of the grains (Figures 13 and 14). These features superimpose upon any pre-existing surface textures and so add to the specific chronology of events to be recognized from the study of quartz grain surface textures. There are many different forms that these chemical features can take, with perhaps forty or more different features recognized from a whole gambit of specific chemical environments [6].

The grain alterations outlined above represent some of those features found on quartz grain surfaces which can be formed during the procession of a grain from its source rock to its deposition in a soil where it can become relevant for forensic science. Two other additions to the grain surface can add further surface texture character to a quartz grain. These are the diagenetic alteration of grains (formed when a sediment undergoes transformation into a rock), and the direct anthropogenic (man-made) effects imparted onto quartz sand grain surfaces.

The diagenetic alteration of sediments impart features on the quartz sand grains which are preserved when it is released from its parent rock by weathering or erosion. Simply, if a quartz grain derives from a sandstone which had originally been a wind-blown deposit, the grain will understandably start its new cycle of erosion with the qualities of a wind-blown grain. Whilst the smallest textures may not survive this diagenetic phase, macro features such as grain shape or roundness normally do. Subsequent transportation will overlay further suites of surface textures, thus making the quartz grain texture sequence even more complicated than that described above.

There is an added series of textures that are imparted upon a quartz grain surface during the process of rock formation (diagenesis) and these may enable the experienced analyst to 
Figure 14 SEM micrograph of quartz sand grain exhibiting quartz precipitation. Scale bar 30 microns.

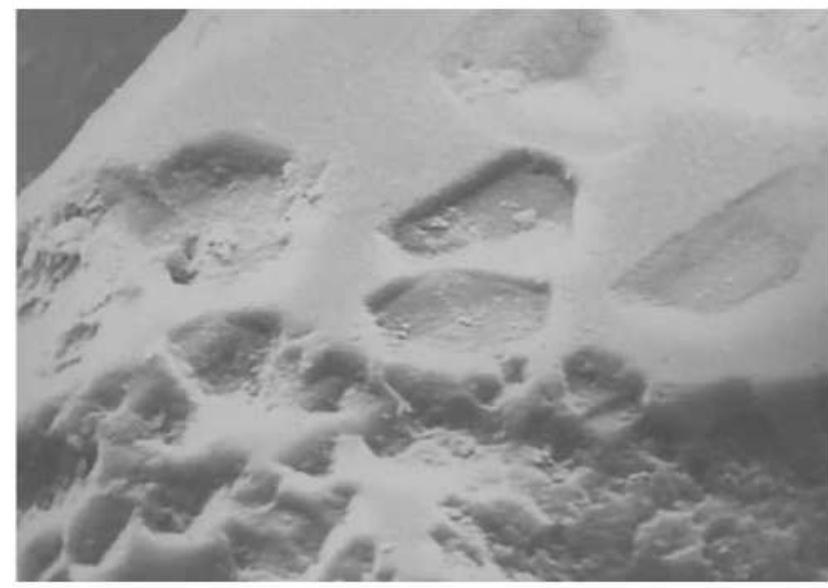

Figure 15 SEM micrograph of quartz sand grain exhibiting authigenic euhedral quartz overgrowth with no edge abrasion. Scale bar 10 microns.

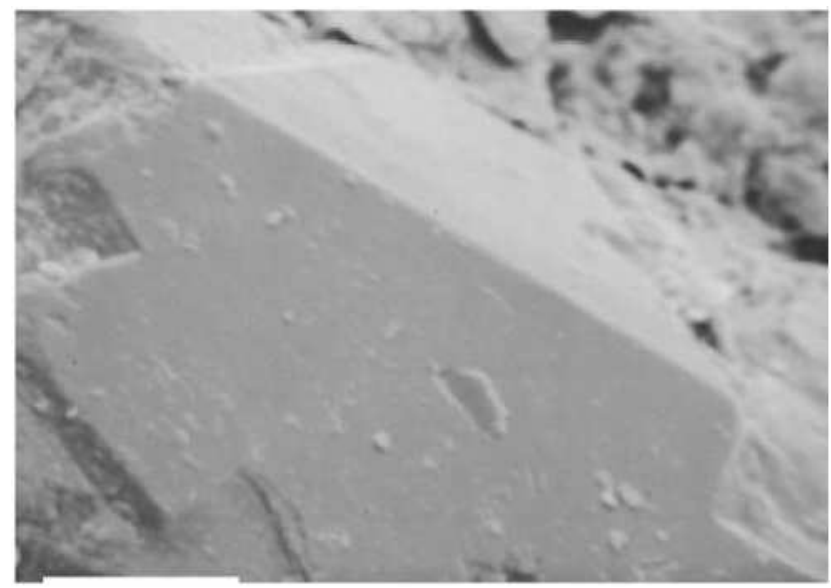

Figure 16 SEM micrograph of quartz sand grain exhibiting authigenic euhedral quartz overgrowth with edge abrasion. Scale bar 50 microns.

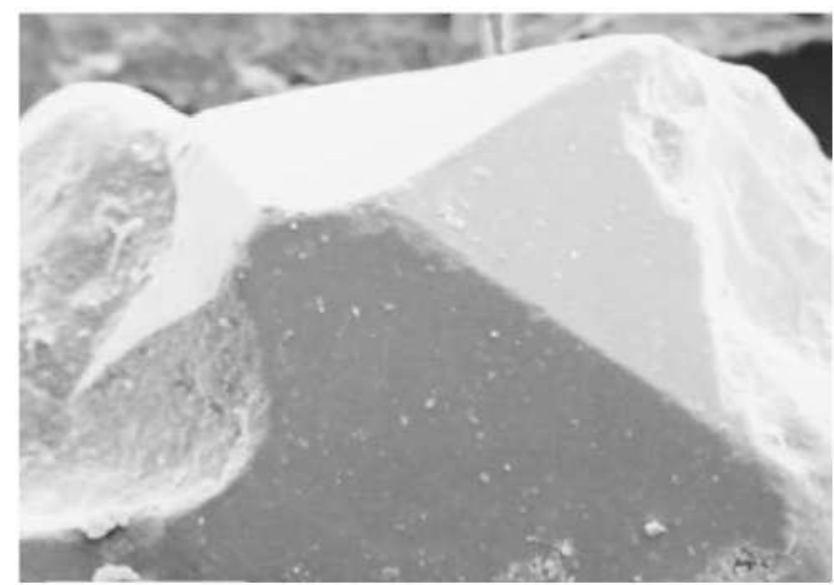

Figure 17 SEM micrograph of quartz sand grain exhibiting authigenic euhedral quartz overgrowth with both chemical and mechanical edge abrasion. Scale bar 10 microns.

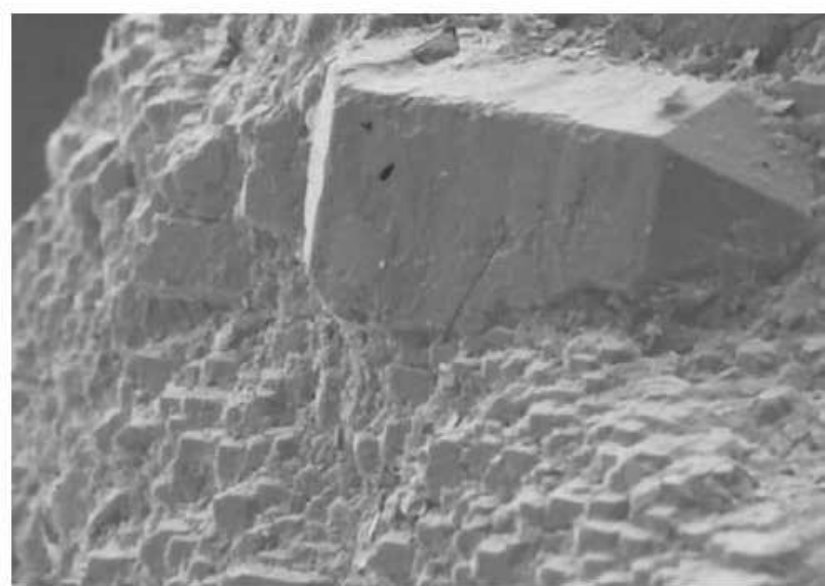

identify the source (provenance) of the sediment parent rock [7] [8]. Whilst the surface texture reconstruction technique provides a logical geological story for forensic science, it is the ability to trace the provenance of a sediment which is of greater importance.

There are a number of surface textures which are produced during diagenesis which are very distinctive and the release of a grain from its parent rock will initially provide completely fresh and unabraded textures (Figures 15). Subsequent edge abrasion can occur in a matter of 10 metres or so by the action of rain wash down a slope (collu viation) (Figure 16 and 17). These can prove crucial in forensic reconstruction, enabling provenance to be identified within metres of the original source. Given that there are literally hundreds of different rock types in Britain alone, large-scale provenance indications are also possible.

The second additional quartz grain surface textures are those imparted by human activity. Such anthropogenic additions take the form of direct textures (ploughing, crushing by vehicle tyres etc.) and indirect intervention by the addition of exotic quartz grains (building activities, specialist garden and other horticultural soils, industrial quartz etc). These categories are extremely important in the reconstruction of forensic scenes in cities, towns and villages as well as in the vicinity of roads, buildings (ancient or modern), parks and gardens.

\section{Procedures}

The collection of samples for quartz grain surface analysis is an important step in the accurate forensic reconstruction of a soil or sediment. However, procedures of sample collection, sites of collection, preparation of samples and even the analytical methods vary from those procedures adopted for environmental reconstruction in geological studies. These variations also affect subsequent interpretative analysis. 


\section{Collection Procedures}

The main difference in sample collection between geological and forensic investigations is that of the availability of the amount of a sample. There is a plentiful supply of soil or sediment in gardens and fields which can be sampled for forensic analysis. However, it must be remembered that only the representative surface material (a few centimetres) should be taken if the desire is to compare this material with soil or sediment found on a person, their clothing or property. Indeed, the collection of material from a person or their property normally involves very small amounts of material and unlike geological sample sites, this often includes sampling clothing, cars, domestic appliances, shoes and a host of other anthropogenic sources. Therefore, the preparation of samples will be governed by the constraints of sample size whilst the analysis of the sample needs to take account of any possible mixing through subsequent anthropogenic introductions.

\section{Laboratory Procedures.}

The standard geological preparation techniques employed for quartz grains prior to analysis involve the removal of all adhering particles from the grain surface and the cleaning of the grain in order that as much of the grain surface as possible is available for viewing [7]. It is imperative, however, for the purposes of forensic analysis that no preparation techniques are employed other than gentle washing in cold, distilled water. Lack of conventional preparation does not negate the technique, rather it enables a crucial insight into the nature of the clays, pollen and other micro-debris, which tenaciously adhere to quartz sand grains even during transportation. If it proves necessary to clean the quartz grains after primary inspection, it is a simple matter to conduct this procedure.

Prior to analysis, using a scanning electron microscope to facilitate high magnification investigation, the quartz grains may be coated in gold to aid picture resolution. Some machines do not require gold coating. Some $\mathrm{x}$-ray analyses of elements identified on the grain surfaces during analysis may require that the grains are carbon coated.

It is also important to consider the number of grains to be analysed in order to adequately reflect the character of a sediment or soil. There has been much attention paid to this matter in geological studies and it is, of course, pertinent for forensic analysis. Geological and forensic approaches do not seek the same end product. Geological palaeoenvironmental reconstruction studies attempt to identify the geological history of an area through the study of a number of quartz grain surfaces. However, forensic studies reflect the description of a suite of textures on a grain and seek to identify the number of different types of grain which can be identified (see below). Grain characteristics are used as a comparison technique and are primarily used to exclude samples from having originated from a source similar to that of the comparator sample. The exclusion approach should be the fundamental tenet of geoforensic analysis.

Ideally, as many grains as possible should be analysed to reflect the population of a sample and for geological studies,

experienced researchers have suggested different numbers. In the early years (1960-1970) 10 grains were universally used for each sample and this proved adequate in many palaeoenvironmental studies [9]. As it became easier to prepare and analyse the samples with new and improved electron microscopes, more grains were studied; 30 grains were deemed statistically appropriate [10]. It is interesting to note the conclusions of hundreds of papers published in the early years (1960-1970) stood the test of time, with few if any having their results contradicted because of inadequate sample size. Current convention is that 30 grains are sufficient. A few studies have gone to extremes advocating 100 grains were necessary for analysis [11], but these studies have dealt with rather specific environments.

Forensic analysis concentrates more on quartz grain surface morphology and mixing and as such does not attempt the reconstruction of the geological environment (but this does not imply that grain numbers are not important). It is most certainly true that, under certain circumstances, one or two grains can prove to be a vital piece of evidence, but this is not to underplay the importance of reflecting the representative mixing of a sediment. In many cases, 10 grains reflect the type of grains present in a sample and so 30-50 grains analysed in that sample will enable confidence when attempting to draw conclusions. Much depends upon the nature of the sample. Whilst some individual researchers have suggested using up to 100 or more grains per sample, there is no statistical rationale behind this reasoning. A simple analysis of pertinent samples from any particular forensic investigation could provide a graph of diminishing returns relevant for that case.

\section{Analytical Procedures}

The early work concerning electron microscopy of quartz grain surface textures was conducted in the 1960s. It concentrated on visual identification of features on quartz taken from known locations (deserts, rivers, glaciers, etc) in order that they could be compared with other samples so that environmental reconstruction of that area could be achieved. There were many hundreds of papers published in the subsequent 20 years enabling the refining of the technique [3].

Following the pioneering work of Krinsley and Margolis [12], a quantitative methodology was developed which utilized the recognition of the presence or absence of a list of surface textures identified on a quartz grain (Table 1). This procedure had merit in that it concentrated the attention of the operator upon the whole variety of textures which could be found on the surface of a grain. Quantitative analysis of the data collected in this manner proved that the eventual diagnosis of grain history was very good, even with inexperienced operators [13]. The problem with this type of quantification was that it only provided a description of the features found on the grain. It failed to account for the various cyclic events that superimposed suites of textures upon pre-existing features as the conditions changed during the 'life-cycle' of the quartz sand grains. Further, it prevented identification of different types of grain and therefore, gave no indication of the degree of mixing and the sources of individual grains found within a sediment body.

Figure 18 Distribution of sample site locations for database 
(www.geog.ox.ac.uk/research/smf). Various numbers of samples are represented by each location circle.

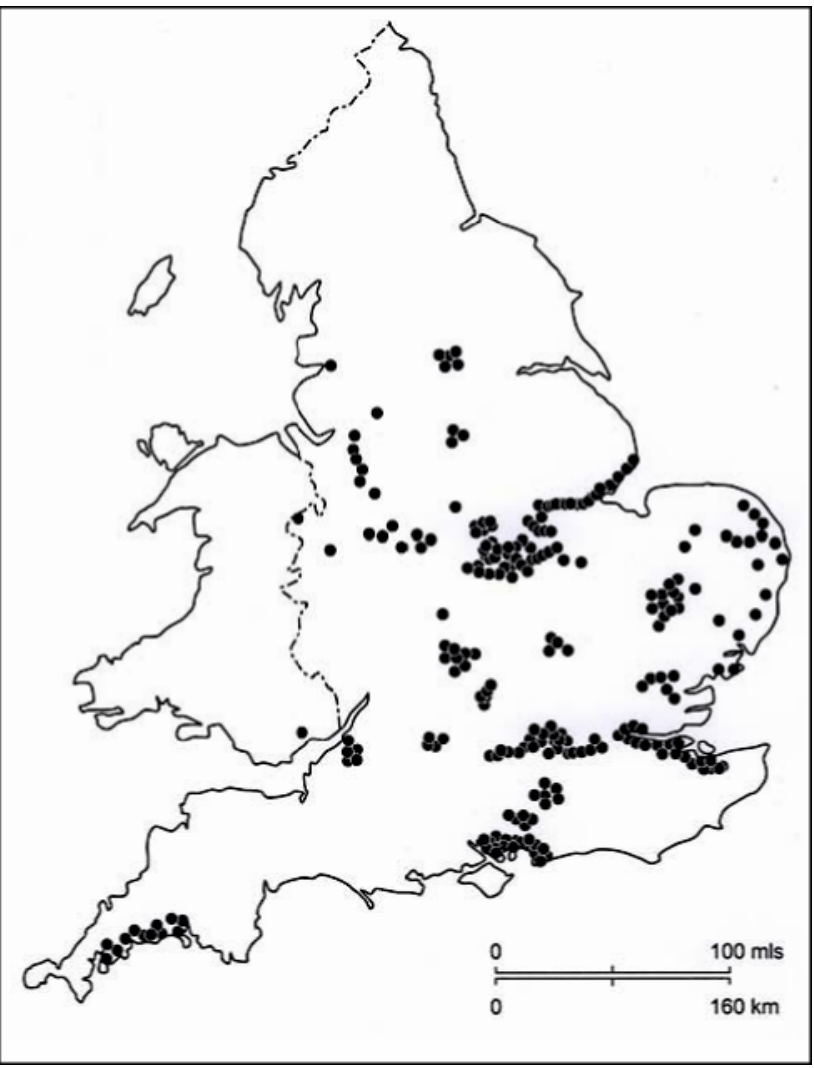

Table 2 Quartz grain type presence or absence tables used for court data presentation

\section{QuartzGrain Types}

\section{Sampledescription I II III IV V VI VII VIII IX An}

indication of the degree of mixing of sediment and the source of individual grains is fundamental for forensic comparison.

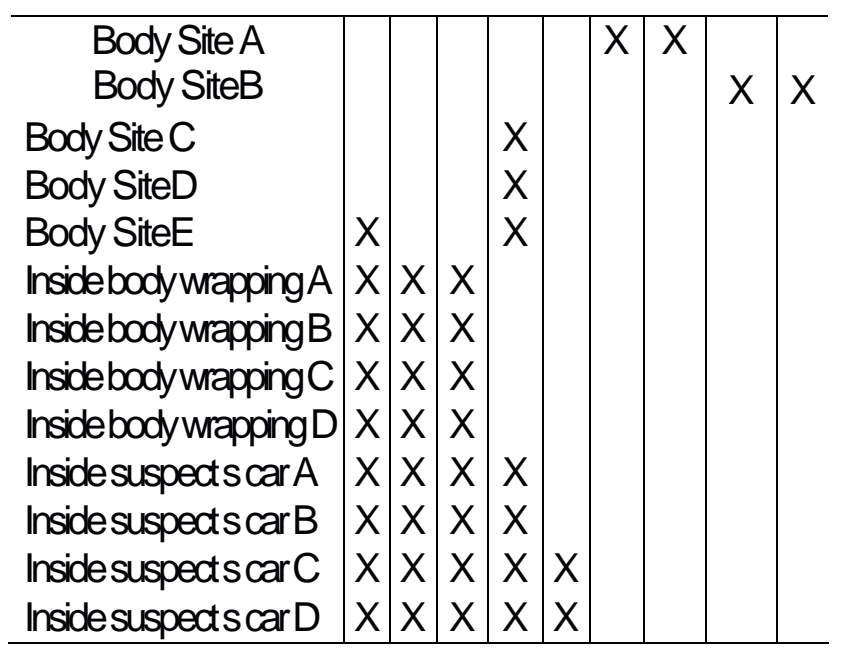

\section{Results}

Quartz Grain Types

For the purposes of this paper, 20 case studies are discussed in the context of quartz grain surface texture analysis which inevitably represents only one of many lines of evidence (including other sedimentological techniques) employed for the presentation of each case study for court. The study involves the analysis of 738 individual samples taken during, or subsequent to, the presentation of each report. In total, approximately 25,000 individual quartz sand grains were analysed for their surface textural assemblages. This involved identifying the relative occurrence, on those sand grain surfaces, of approximately 1 million surface textures.

In order that a jury could understand the technicalities of surface texture analysis, the raw data obtained for each case was summarised such that the major quartz grain types found in each sample could be categorised and presented in a very simple manner (Table 2). This categorisation and summary of features took a simple descriptive form (which also maintained geological integrity; other papers which utilise this grain type approach include [14][15][16][17]). By way of example, a grain type I could be designated as a very well rounded grain with impact features (caused by river transportation), and subsequent grain surface solution (caused by soil acids following deposition). Similarly, a grain type II could be designated as a very angular grain with no edge abrasion (derived from a rock comprising of angular grains) with crystal growths on the surface of the grain (diagenetic features formed when the nearby sandstone had been turned into a rock many millions of years ago). Thus, it would be possible to explain to a jury that the rounded type I grains found on the shoes and clothes of the accused could not have come, as may have been claimed, from the garden of the defendant, as this was made up of grains of type II origin. Thus an alibi exclusion could be provided. It would be worthy to note also that if the type I grains found on the shoes and clothes of the accused were similar in type to those found at the deposition scene where a body had been

Figure 19 Frequency histogram of the number of grain types per sample at the 5 th order of classification compiled from the database (www.geog.ox.ac.uk/research/smf).

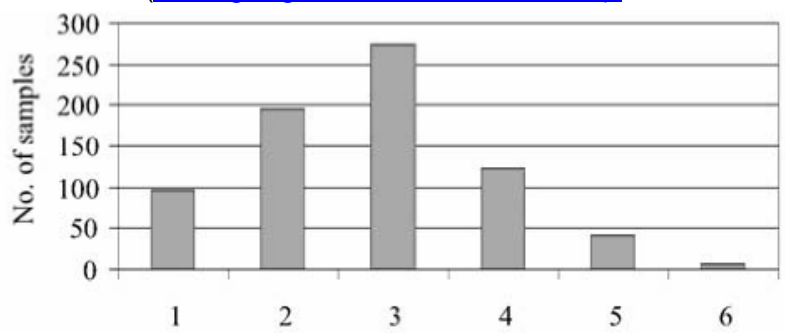

No. of grain types per sample. $n=738$ mean 2.78 sd 1.11 buried in a shallow grave, then a similarity between samples could be identified. (Of course, what is of importance would be an appreciation of how unusual the type I grains were. In reality, soil samples tend to contain a combination of grain types, thus increasing the individuality of a site.) 
The case studies used for this paper are all taken from England, with the exception of one case from Cardiff, Wales (Figure 18), and represent analyses undertaken both for court work and as forensic experimental studies of soils and sediments associated with individual cases. The samples collected were initially taken over a 12 year period and the analysis of each case was restricted to identifying surface texture analysis of quartz for that particular case only (as outlined above). The compiled sample results obtained for this paper were collected therefore, in a 'blind' analysis with no a priori knowledge during the initial investigations. Specific grain type classifications were constructed for each case independent of other grain types which had been formulated for previous investigations. Thus, the presentation of results to court will take the form as presented in Table 2. Here the presence or absence of a grain type may be noted for a particular sample so that comparison can be made between samples and exclusions can be evoked. The total amalgamation and standardisation of grain types has occurred only for this paper and are presented in Table 3. Here, four main groups are identified (at 1st order classification); angular grains, rounded grains, metamorphic grains (those exhibiting strain induced shapes) and chemically modified grains designated $\mathrm{A}$ $\mathrm{B}, \mathrm{C}$ and D. Each 1st order group is subdivided into a 2nd order classification. These are designated A1, A2, A3 and B 1, B2, B3 etc. A 3rd, 4th and 5th order subdivision is primarily concerned with whether the grains are edge abraded, edge rounded, or neither. This descriptive classification has been retrospectively applied to all samples and all grains analysed fit into one of these divisions. It is possible also to provide a percentage number of grains that exhibit a particular grain type although this may provide false detail (see discussion later).

\section{Grain Type Frequencies}

The assembly of previous cases highlighted a number of interesting statistics related to the number of grain types found in forensic (and geologic) samples. Construction of a frequency histogram of all 738 analysed samples (Figure 19) provides a positively skewed sample population where it is clear that there are surprisingly few grain types in each sample. Rarely are there more than four grain types found in a sediment sample and more typically there are three or less. Indeed, those samples that exhibited larger numbers of grain types per sample often comprised those that had anthropogenic additions (typically, the driver's footwell of a car often contained larger numbers of grain types reflecting the varied provenance of materials picked up on the driver's shoes as he entered the car on each occasion).

In all, a quartz grain will ultimately be classified into one of 23 grain types (e.g. A3biid will be a high-relief angular grain of microcrystalline form showing both edge rounding and abrasion. The grain cannot be any other designation in the A3 (2nd order) classification). So with a possibility of 23 grain types identified in this paper, the paucity of variation of grain types per sample portrayed in Figure 19 is indeed striking. This implies that grain mixing from different sources is discrete and ordered, rather than chaotic and mixed.

\section{Grain Type Database}

The 738 samples analysed by scanning electron microscopy for their quartz grain surface textures were categorised according to the full 5 order classification involving over 80 permutations of grain type (Table 3). The full table which also incorporates the number of grains in each sample analysed can be viewed at www.geog.ox.ac.uk/research/semf/. Compiled from this database are the numbers and percentages of grains found in each level of grain type classification. These are presented in summary form in Table 4 . Over $61 \%$ of all grains investigated show soil or diagenetic features (1st order category D) with approximately $21 \%$ of grains as 1 st order category $\mathrm{B}$, subaqueous or aeolian rounded grains. Whilst angular grains comprising quartz (from granite (A1), glacial materials (A2), or fragmented grains released during weathering from a rock (A3)) represent $16.6 \%$ of all grains analysed, only $0.2 \%$ of grains exhibit metamorphic (1st order C) characteristics. Metamorphic grains in this classification involve those which have been elongated or altered by high pressure and temperature during the deformation of metamorphic rocks. The low number of grains in this category can be explained by the paucity of metamorphic rocks in England. This inevitably affects the final shape of the grain and these are often far more distinctive than the angular or rounded quartz grains of other classifications. The very distinctively shaped metamorphic provenance grains are far more abundant in Wales and Scotland. Table 4 therefore, represents a summary of the provenance of surficial sediments in England. For example, at the 3rd order classification $45.6 \%$ of all sand grains studied showed diagenetic features (D1a; 3rd order classification) which indicates that the grains have eroded from a parent sedimentary rock. Distinctive crystal overgrowths, also associated with diagenetic processes, are found on a further $11.2 \%$ of grains. Thus diagenetically derived quartz grains are found on $56.8 \%$ of quartz sand grains studied in these forensic cases. The presentation of results to court will take the form as presented in Table 2. Here the presence or absence of a grain type may be noted for a particular sample so that comparison can be made between samples and exclusions can be evoked.

\section{Grain Type Assemblages}

The hypothetical scenario explaining an alibi-exclusion mentioned above utilises a situation where only one grain type is found. Indeed, Table 2 presents a real life situation, where a number of grain types designated for a case are presented in a tabular form for the jury. The table is by necessity somewhat abridged for this example. A body was found in a river, wrapped in material. Sediment samples taken in the vicinity of the body site exhibited two different assemblages of quartz grain types. Body site A and body site B contained grain types VI, VII, VIII and IX, whilst closer to where the body was found the sediment exhibited primarily type IV. Sediment recovered from inside the body wrapping contained grain types I, II and III. Thus, it could be shown that these materials could not have

originated from the same source as those found in sediments around the vicinity of where the body was found. Investigation of the interior of a suspect's car showed that the same quartz grain types found inside the body wrapping were also found inside the suspect's car. In addition, the material from inside the suspect's car contained the same quartz grain types as designated from sediments in the vicinity of the body site. Two samples from inside the suspect's car contained these four grain 
types, but also contained a fifth grain type and this latter grain type could be considered to be from a different provenance. Exclusion of materials in the vicinity of the body site could be evoked with materials taken from inside the body wrapping. The similarity between materials within the body wrapping together with those found inside the suspect's car were noted, but it could not be concluded that they positively derived from the same source of material. By comparison with the database (www.geog.ox.ac.uk/research/semf) it could be ascertained as to the relative individuality of the combination of grain types in each sample. But since exclusion rather than matching of samples was the intention of this investigation, such statistical evaluation was not carried out at the time.

It would be possible to provide Table 2 with the actual grain type designations as presented here in Table 3. However, the geological nomenclature would provide unnecessary detail for the consideration of the jury. Similarly, it would also be possible to provide Table 2 with the actual percentages of grains in each sample which were designated to each of the grain category types. Experience shows that such detail can mask the overall picture, although as shown below, by utilising such methods surprisingly compelling statistics can be derived. Whether such analysis provides false positive or false negative results will be discussed later.

A summary table (Table 5) constructed from the database (www.geog.ox.ac.uk/research/semf) portrays the number of quartz grain types found in a sample at different orders of classification. At the 5th order of classification seven samples contained six grain types. It is interesting to note that six of these seven samples were taken from clearly anthropogenically affected locations (cars, clothing etc.) and at the same 5th order of classification, 38 of the 42 samples which had five grain types were also derived from anthropogenic sources.

Figure 20 Ternary plot for the ratio of grain types at the 2 nd order classification. Black dots indicate samples taken from the victim and deposition site; open squares indicate samples taken from vehicle 1; closed squares indicate samples taken from vehicle 2 .

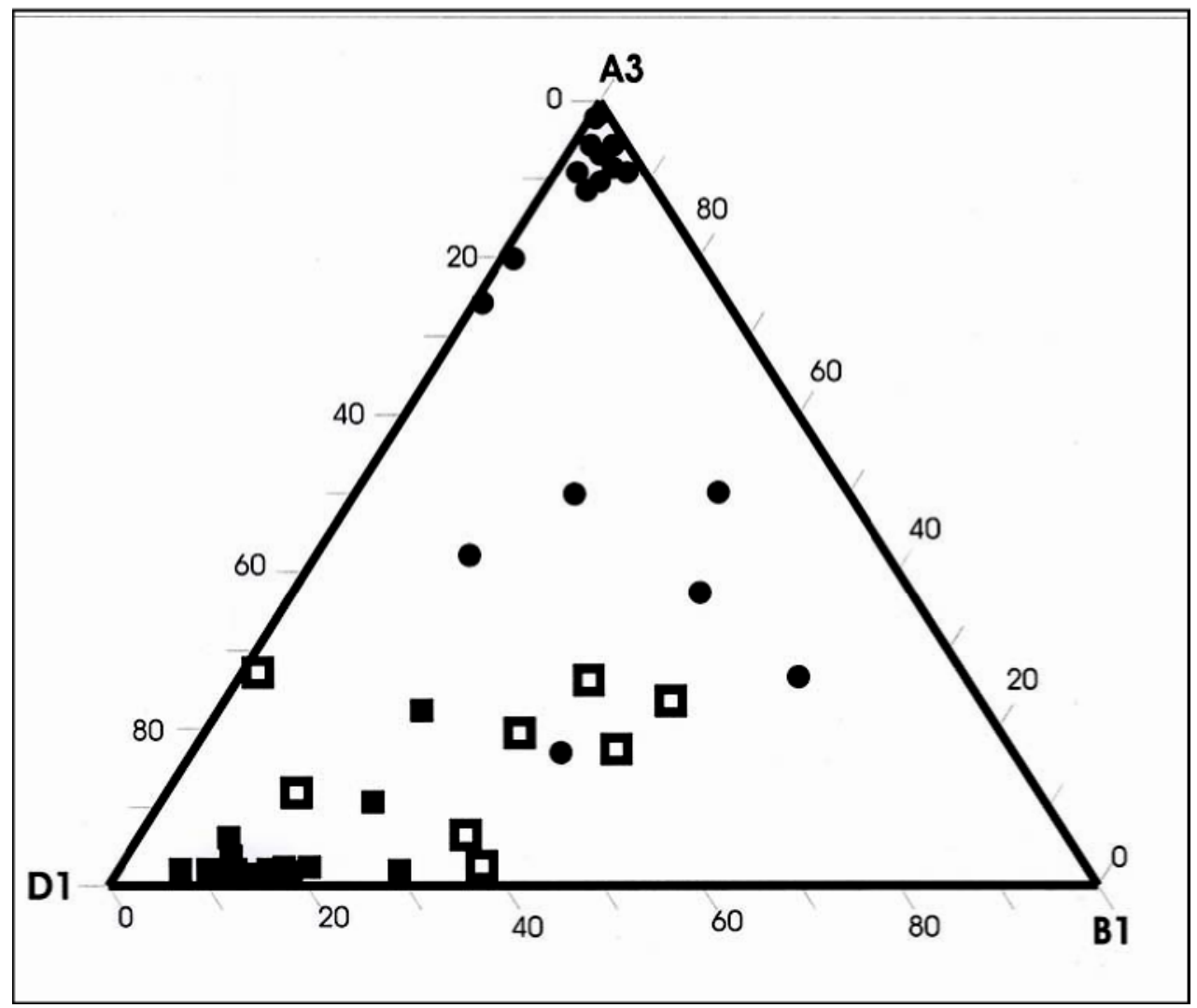

- Victim and Site Samples 
Table 3 5-order classification of quartz grain types
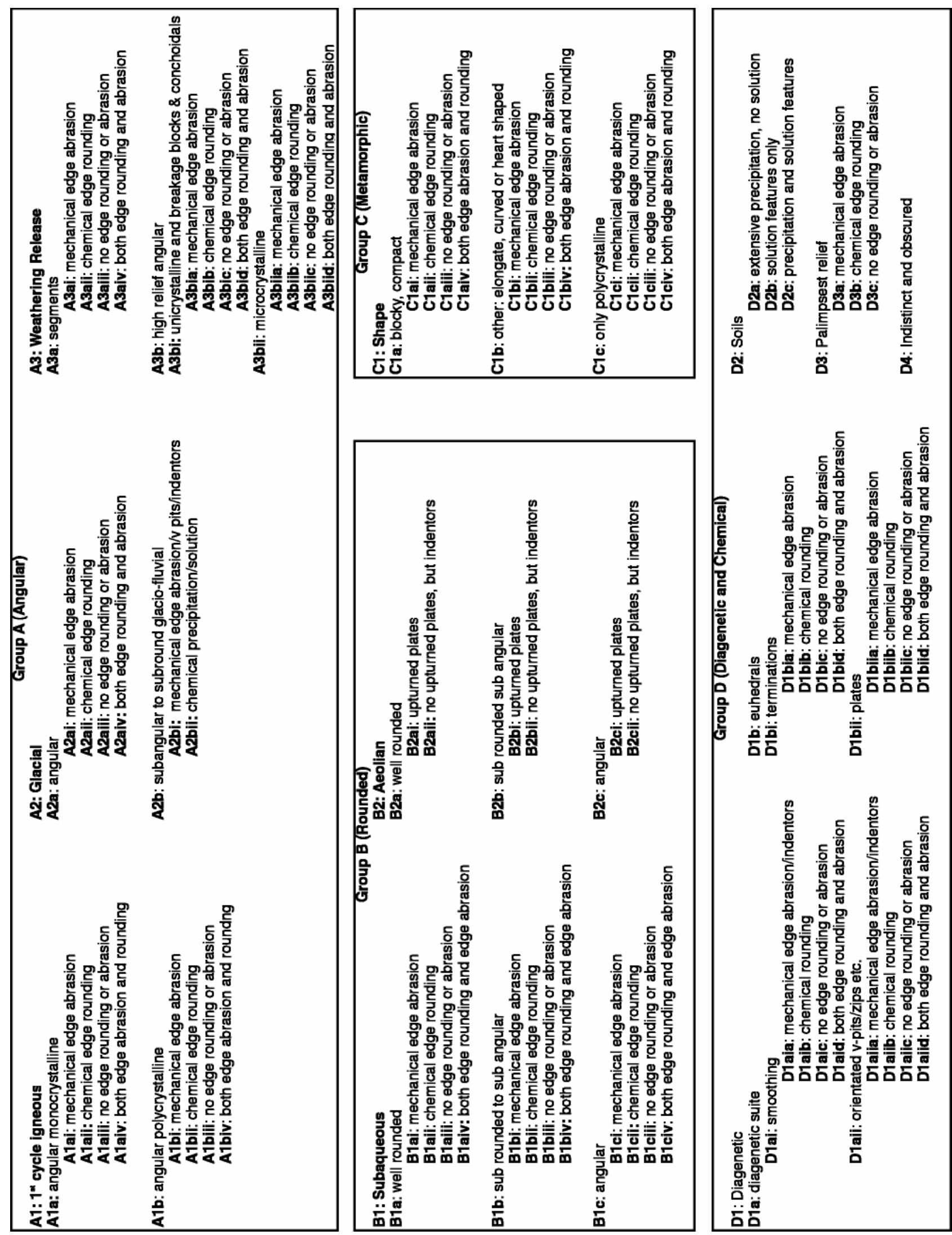
Table 4 Percentage occurrence of the 5-order classification of quartz grain types compiled from the database (www.geog.ox.ac.uk/research/smf). $n=738$

\begin{tabular}{|c|c|c|c|c|c|c|c|c|c|c|}
\hline \multirow{22}{*}{$\begin{array}{ll}\text { A Angular } \\
\text { A1 } 1 \text { st Cycle } \\
\text { A2 } & \text { Glacial } \\
\text { A3 } & \text { Weathering Release }\end{array}$} & \multirow{22}{*}{ A } & \multirow{6}{*}{ A1 } & \multirow{3}{*}{ A1a } & A1ai & & 0.0 & 0.0 & \multirow{3}{*}{0.0} & \multirow{6}{*}{0.0} & \multirow{22}{*}{16.6} \\
\hline & & & & A1aii & & 0.0 & 0.0 & & & \\
\hline & & & & A1aiii & & 0.0 & 0.0 & & & \\
\hline & & & \multirow{3}{*}{ A1b } & A1bi & & 0.0 & 0.0 & \multirow{3}{*}{0.0} & & \\
\hline & & & & A1bii & & 0.0 & 0.0 & & & \\
\hline & & & & A1biii & & 0.0 & 0.0 & & & \\
\hline & & & & A2ai & & 0.0 & 0.0 & & & \\
\hline & & & A2a & Azaii & & 0.0 & 0.0 & 00 & & \\
\hline & & ? & ALd & A2aiii & & 0.0 & 0.0 & 0.0 & n & \\
\hline & & AL & & A2aiv & & 0.0 & 0.0 & & 0.0 & \\
\hline & & & $A 2 \mathrm{~b}$ & A2bi & & 0.0 & 0.0 & 00 & & \\
\hline & & & & A2bii & & 0.0 & 0.0 & 0.0 & & \\
\hline & & & & A3ai & & 0.0 & 0.0 & & & \\
\hline & & & A3a & A3aii & & 0.1 & 0.1 & 0.1 & & \\
\hline & & & & A3aiii & & 0.0 & 0.0 & & & \\
\hline & & & & A3aiv & & 0.0 & 0.0 & & & \\
\hline & & A3 & & & A3bia & 1.5 & & & 16.6 & \\
\hline & & & & A3bi & A3bib & 8.8 & 15.6 & & & \\
\hline & & & $\mathrm{A}^{3} \mathrm{~b}$ & & A3bic & 5.3 & & 16.5 & & \\
\hline & & & . & & A3blia & 0.0 & & & & \\
\hline & & & & A3bii & A3biib & 0.7 & 0.9 & & & \\
\hline & & & & & A3blic & 0.2 & & & & \\
\hline & & & & B1ai & & 0.1 & 0.1 & & & \\
\hline & & & B1a & B1aii & & 3.0 & 3.0 & 97 & & \\
\hline & & & & B1aiii & & 0.0 & 0.0 & 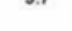 & & \\
\hline & & & & Braiv & & 6.6 & 6.6 & & & \\
\hline & & & & B1bi & & 0.7 & 0.7 & & & \\
\hline B Rounded & & B1 & B1b & B1bii & & 0.0 & 0.0 & 10.9 & 21.1 & \\
\hline B1 Subaqueous & & & & B1biii & & 0.0 & 0.0 & & & \\
\hline B2 Aeolian & & & & Bibiv & & 10.2 & 10.2 & & & \\
\hline & B & & & B1d & & 0.0 & 0.0 & & & 21.3 \\
\hline & 0 & & B1C & B1cii & & 0.0 & 0.0 & 0.5 & & \\
\hline & & & & B1ciii & & 0.0 & 0.0 & & & \\
\hline & & & & B1civ & & 0.5 & 0.5 & & & \\
\hline & & & B2a & Bzai & & 0.1 & 0.1 & 0.9 & & \\
\hline & & & & Bzaii & & 0.0 & 0.0 & & & \\
\hline & & B2 & $B 2 \mathrm{~b}$ & B2bi & & 0.1 & 0.1 & 0.1 & 02 & \\
\hline & & & & B2bii & & 0.0 & 0.0 & & & \\
\hline & & & $B 2 c$ & B2d & & 0.0 & 0.0 & 00 & & \\
\hline & & & & B2cii & & 0.0 & 0.0 & & & \\
\hline & & & & Crai & & 0.0 & 0.0 & & & \\
\hline & & & C1a & \begin{tabular}{|l|l|} 
C1aii \\
\end{tabular} & & 0.0 & 0.0 & 00 & & \\
\hline & & & & 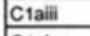 & & 0.0 & 0.0 & . & & \\
\hline & & & & Craiv & & 0.0 & 0.0 & & & \\
\hline C Metamorphic & & & & Cibi & & 0.2 & 0.2 & & & \\
\hline Cl Shape & c & C1 & $\mathrm{C}_{1 \mathrm{~b}}$ & C1bii & & 0.0 & 0.0 & 0.2 & 0.2 & 0.2 \\
\hline & & & & \begin{tabular}{|l} 
C1biii \\
Cibiv
\end{tabular} & & $\frac{0.0}{0.0}$ & 0.0 & & & \\
\hline & & & & c1d & & 0.0 & 0.0 & & & \\
\hline & & & C1c & \begin{tabular}{|l|l|} 
Cicii \\
C1ciil
\end{tabular} & & $\frac{0.0}{00}$ & 0.0 & 0.0 & & \\
\hline & & & & \begin{tabular}{|l} 
Cidiv \\
\end{tabular} & & $\frac{0.0}{0.0}$ & 0.0 & & & \\
\hline & & & & & D1aia & 7.5 & & & & \\
\hline & & & & & \begin{tabular}{|l|l|} 
Diaib \\
\end{tabular} & 8.7 & 32.3 & & & \\
\hline & & & & Diai & \begin{tabular}{|l} 
Oraic \\
Daiaid \\
\end{tabular} & $\frac{0.2}{159}$ & & & & \\
\hline & & & Dia & & Dialia & 1.1 & & 45.6 & & \\
\hline & & & & & D1ailib & 1.1 & 133 & & & \\
\hline & & & & D1aii & $\begin{array}{l}\text { D1alic } \\
\text { Daic }\end{array}$ & 0.0 & & & & \\
\hline & & D1 & & & \begin{tabular}{|l|l|} 
Drbiala \\
\end{tabular} & $\frac{11.1}{1.1}$ & & & 56.8 & \\
\hline D Chemical & & & & & D1bib & 1.8 & $5 ?$ & & & \\
\hline D1 Diagenetic & & & & & D1bic & 0.5 & 5.2 & & & \\
\hline D2 Soils & D & & D1b & D1bi & Dibid & 1.9 & & 112 & & 61.7 \\
\hline D3 Palimpsest & & & & & D1bilia & 1.4 & & & & \\
\hline D4 Obscure & & & & & \begin{tabular}{|l|l|} 
D1bilib \\
\end{tabular} & 2.2 & 6.0 & & & \\
\hline & & & & D1bii & \begin{tabular}{|l|} 
D1bilic \\
D1tid \\
\end{tabular} & $\frac{0.0}{24}$ & & & & \\
\hline & 3 & & D2a & & & 0.8 & 0.8 & 0.8 & & \\
\hline & & D2 & $\mathrm{D} 2 \mathrm{~b}$ & & & 0.0 & 0.0 & 0.0 & 2.7 & \\
\hline & & & $\mathrm{D} 2 \mathrm{C}$ & & & 1.9 & 1.9 & 1.9 & & \\
\hline & & & D3a & & & 0.0 & 0.0 & 0.0 & & \\
\hline & & D3 & D3b & & & 0.0 & 0.0 & 0.0 & 2.0 & \\
\hline & & & $\mathrm{D} 3 \mathrm{c}$ & & & 2.0 & 2.0 & 2.0 & & \\
\hline & & D4 & & & & 0.2 & 0.2 & 0.2 & 0.2 & \\
\hline
\end{tabular}


Whether a particular order of classification utilised is discrete enough to identify the characteristics of a sample compared to that of other comparator samples is the most important point to consider in forensic analysis. If it were possible to different iate samples at 1st or 2nd order of classification rather than at 4th or 5 th order classification, analysis time could be decreased dramatically and automation would be a likely possibility. Since the grain type assemblages discussed above relate to within-case examples, it is useful to consider the between-case associations of grain type assemblages in order that the individuality of a particular grain type assemblage within a sample can be related to the whole database. A simple binary recognition program was added to the database (www.geog.ox.ac.uk/research/semf) in order that betweencase similarities could be identified. The results of this analysis are presented in Table 6 . Here, the between-case samples of different grain types analysed at different orders of classification are presented as a percentage of the number of samples (identified in Table 5) which are not duplicated in other cases. As would be expected, those samples that contain only one grain type are found in other cases more frequently than samples that contain larger numbers of grain types. Surprisingly, at the first order of classification, samples with one grain type still provided $71 \%$ non-duplication in samples between cases. The modal class of grain types found in a sample as portrayed in figure 19 is three and here, very high non-duplication percentages are recorded at all orders of classification. Since the sample size is 738 these percentages indicate a very diagnostic exclusionary technique.

Using a hierarchical cluster technique, all samples from the database (www.geog.ox.ac.uk/research/semf) were classified into groupings of dissimilarity. All 20 cases were included in the cluster analysis, but no between-sample clusterings occurred. Whether it is wise to continue this statistical analysis to infer greater meanings is a moot point. This black box approach could perhaps be unflatteringly described as GIGO (Garbage In, Garbage Out).

\section{Grain Type Assemblage Percentages}

So far in this paper we have been concerned with the identification of grain types and their occurrence in a sediment sample. This has been used, as in Table 2, to provide presence or absence data in order to exclude a sample from having derived from a similar provenance as that of a comparator sample. The natural extension to this study is to consider now the ratio of grain types to each other within a sample. There are advantages and disadvantages of doing this since there are basic geological assumptions that have to be made in order that valid

Table 5 Frequency of the number of samples containing different numbers of grain types at different orders of classification compiled from the database (www.geog.ox.ac.uk/research/smf)

\begin{tabular}{cccccc}
\hline & \multicolumn{5}{c}{ Number of Samples } \\
\hline $\begin{array}{c}\text { Number of Grain } \\
\text { Types }\end{array}$ & 1st order & 2nd order & 3rd order & 4th order & 5th order \\
\hline 1 & 213 & 174 & 105 & 90 & 55 \\
2 & 357 & 324 & 216 & 176 & 55 \\
3 & 150 & 148 & 196 & 102 & 12 \\
4 & 0 & 11 & 39 & 0 & 0 \\
5 & - & 0 & 7 & 0 & 0 \\
6 & - & - & 0 & 0 & 0 \\
\hline
\end{tabular}

Table 6 Percentage frequency of the number of samples containing different numbers of grain types at different orders of classification which are not duplicated between the 20 cases. Compiled from the database (www.geog.ox.ac.uk/research/smf)

\begin{tabular}{cccccc}
\hline \multicolumn{7}{c}{ \% Number of Samples which cassespot dupticated between cases } \\
\hline $\begin{array}{c}\text { Number of Grain } \\
\text { Types }\end{array}$ & 1st order & 2nd order & 3rd order & 4th order & $\mathbf{5}^{\text {th }}$ order \\
\hline 1 & 71.1 & 76.4 & 85.8 & 87.8 & 92.5 \\
2 & 51.6 & 56.1 & 70.7 & 76.2 & 92.5 \\
3 & 79.7 & 79.9 & 73.4 & 86.2 & 99.9 \\
4 & 100.0 & 98.5 & 94.7 & 100.0 & 100.0 \\
5 & - & 100.0 & 99.1 & 100.0 & 100.0 \\
6 & - & - & 100.0 & 100.0 & 100.0 \\
\hline
\end{tabular}


comparisons can be drawn. Primary amongst these assumptions is that not only are we considering that two samples with the same combination of grain types derive from similar provenance, but also that they derive from a similar provenance which itself has a uniform and non-varying ratio of quartz grain types within its sediment or rock body. If differentiation between samples is undertaken on the basis of a variation in the ratio of the quartz grain type percentages, it is crucial that the provenance of the comparator samples contains a uniform ratio of the grain types within the sediment or rock body. This may appear to be a leap of faith too far, although re-analysis of case studies which have been completed yield, in some cases, positive results.

By comparing the ratios of the quartz grain types of 2 nd order classification, as highlighted in Table 3 , triangular diagram plots can be drawn for each sample within a case. Although only 2 nd order classification is being evoked, the computed ternary diagram ratios can provide compelling results (Figure 20).

Figure 20 presents a tripartite ratio plot for three quartz grain types (A3, weathering released grains; B 1, subaqueous grains and D1, diagenetically altered grains). These samples were taken from a case which involved the discovery of a body in a muddy wooded area and the report of a car parked in the area at about the time it was thought that the victim had gone missing. The suspect owned two cars of the same make and both were sampled in order to see whether the sediments found within the car could be compared to material at and about the body deposition site Quartz surface texture analysis was conducted and grain types were identified to a 5 th order of classification. The data were reclassified in the broader 2 nd order classification in order that the ratios could be compared. Figure 20 shows the distribution of all samples analysed for this case. The black dots show the ratio of the three grain types in samples taken from the body of the victim, the site and also the vicinity in the region of the body. In comparison, the open squares show the ratio of quartz grain types taken from samples collected from the inside of vehicle 1 owned by the accused. The closed squares show the distribution and ratio of the same grain types computed from materials collected from within vehicle 2 also owned by the accused. There is a visual grouping of all three sample clusters and using the ratio of grain types coming from vehicle 2 of the suspect (closed squares) it may be possible to exclude these from having derived from the same source as those immediately about the victim's body. Further, it is tempting to consider that the sediment recovered from vehicle 1 has a greater similarity in grain type ratios to that in the area about the body scene. In order that such a conclusion can be reached it must be remembered that there is an assumption that these materials derive from a sediment source which itself is made up uniformly of similar grain type ratios throughout its sediment body. One reason why such success may be drawn in this instance is that the source of the soil and mud in the vicinity of the body was a very nearby weathered sandstone (a matter of only 10 or so metres away), and perhaps the grain type ratios within that discrete rock provenance was uniform.

It is, of course, possible to extend such a nalysis and enthusiastically embrace multiple discriminant techniques in order to regulate the statistical distance both within-sample and between-samples from the triangular plot (Figure 20). Principal component analysis, factor analysis, linear and multiple discriminate analysis and cluster analysis are all available as grouping and discriminant techniques. It would then be possible to ascribe 'statistical' meaning to the differences between groups. Perhaps this is one step too far at the moment as this would take the interpretation past that of exclusion and into the far more hazy area of attempting to match samples by their geological constituents. The formulation of data groupings or clusters is as Davis [18] suggests rather more of a fishing exercise than statistical interpretation.

\section{Discussion}

One of the underlying conceptual themes running through this paper has been that at the outset, quartz surface texture analysis is used to exclude a sample from having derived from the same or similar provenance as its comparator sample. In forensic geoscience it is far more difficult to 'match' the characteristics of two samples than it would be in some aspects of the biological sciences. No two rocks, or even quartz grain surface textures are identical in every way. Although some sort of classification can be employed, this association must itself have geological meaning. The development of quartz grain surface texture types is really a return to the methodology that was employed when the technique was in its infancy, in that when quartz surface texture analysis was undertaken in the 1960s descriptive terminology was used. The introduction of statistical analysis in surface texture studies was introduced in the literature in the 1970s and 1980s [13][19] however, attempts to automate grain texture analysis [20] failed to achieve the hoped-for breakthrough and the time required for preparation and analysis of samples proved unpopular without automation. More recently the designation of quartz grain types as presented in the geological literature [14][15][16][17] has enabled direct comparison techniques to be employed in the forensic arena.

The 1st order classification of grains relates primarily to grain shape (the metamorphic subdivision relates to unusually shaped and distinctively formed quartz grains) whilst the diagenetic classification includes gross changes to both grain shape and grain macro-texture. The further subdivisions to 5 th order classification encompass consideration of the smaller surface textures that can be identified on a grain during or immediately after transportation by one or more geomorphological agents.

Such quartz grain texture classification enables exclusion to be effected between a sample or between a group of samples and their comparator sample or comparator group of samples. Fundamental in this approach is the recognition that forensic geoscience analysis seeks to be descriptive and/or exclusionary. So, description, exclusion and/or the relative diagnostic qualities of a sample are the primary aim of this technique.

This leaves the consideration of similarity or 'match' of samples. It was never envisaged that quartz grain type categorisations could 'match' or provide similarity indices between samples. It was thought that the assumptions of the nature and make-up of the source of a sediment body would 
negate comparisons between the similarity of samples using statistical techniques. What is apparent however, is that with a priori knowledge, patterns and associations can indeed be identified between samples or groups of samples, thus endorsing a general view point or hypothesis which may be put forward by other independent lines of analysis within a particular case. Caution is introduced in the interpretation of the triangular diagram presented in the results section of this paper (Figure 20) simply because the interpretation of these plots is facilitated by an overall knowledge of the results obtained from other lines of evidence which emerged during the case. This information is of course not available at the time of primary analysis and before the preparation of a witness statement and indeed this is for a very good reason. Whether or not the higher level interpretation of the results takes the particular technique of quartz grain classification too far into the realms of conjecture rather than scientific fact is a moot point. Given suitable precautions and procedures, scientific results are not ambiguous nor are they false. It is the interpretation of the results that can far exceed the practical and philosophical limitations of the technique. This comment reiterates that made by Kirk [21]. Little has changed.

\section{Quartz Grain Types and Frequencies}

The identification of 80 grain type subdivisions (5th order) results in 23 mutually exclusive categories being classified. It is evident from Figure 19 that the micro-sedimentalogical characteristics of quartz indicate an ordered movement of sediment bodies both through time and space. Whilst this seems somewhat surprising at the first instance, it reflects only high-magnitude, low-frequency sediment movement [22], with the very high-magnitude events often flushing sediment through river systems to largely different geographical areas. What is apparent is that very few grain types exist and the variations that do occur are often the product of present sedimentary cycle modification due to transportation in rivers, the sea or through modification from pedogenic environments. The categorisation of quartz grain types is not arbitrary, but follows from the vast literature of in excess of 1000 papers published in journals worldwide. Beyond the scope of this paper would be the interesting investigation of whether, with a priori knowledge (and by necessity after the verdict from a forensic case has been delivered), exclusion of groups of samples from their comparator samples would differ given different orders of classification (Table 6). This has some importance for forensic analysis as 1 st and 2 nd order classification can be effected very much quicker than employing a full 5th order classification system. Maybe, such 1 st and 2nd order classification would lend themselves to automated pattern recognition programs now readily available for computer analysis.

\section{Grain Type Assemblages}

Within-sample grain type assemblages are very simple for most natural environment soils and sediment (Figure 19), although the addition of anthropogenic materials, perhaps in the footwell of a car, will result in larger numbers of grain types in a sample

assemblage. This mostly explains those sample grain type assemblages of five and six types found in the database (www.geog.ox.ac.uk/research/semf). Other samples which show five or six grain type assemblages were taken from a particular case where soil/sediment samples contained a mixture of metamorphic sandstones mixed with fluvial deposits of a diagenetic origin. Indeed, in this particular case, it was the diversity of grain types assemblages that characterised both the sample and its comparator samples, since the principle samples were taken from the footwell of a car (varied anthropogenic provenances), sandstone which had been metamorphosed and from fluvial deposits from rocks which had undergone distinctive diagenetic processes.

The limited grain type assemblage percentages categorised as 1st order C (metamorphic) reflect the forensically directed, but geologically and geographically random locations of samples taken in England. Little material has been collected from obvious glacial deposits and these are by their very nature of very varied sources and necessarily exhibit grain type assemblages of 4 or 5 types per sample [23].

Although this paper refers only to forensic samples taken in England (and one case from Wales) similar limited grain type assemblages are found in samples analysed by the authors from all continents of the world ([17] South America; [16], Central Asia, China and the Pacific; [15] Middle East, for example).

\section{Grain Type Ratios, Statistics and Grouping Techniques in Forensic Interpretation}

It is evident using simple ternary diagrams (Figure 20) that despite geological assumptions and intuitions, groupings of different sample types can be shown using grain type ratios. This is perhaps one step further than we had intended for this paper and is indeed only possible with a priori knowledge of other lines of evidence used in the criminal case concerned. This is a step further than what is prepared for a jury (Table 2). The trouble comes when multivariate statistics are used to compare the association of quartz grain type categories against each other and only those that provide the necessary assemblage similarities are used in evidence provided for court. This really does encompass Davis's 'fishing expedition' [18] where he describes the manipulation of patterns of data. It would depend therefore, whether one went fishing for the defence or the prosecution! Unfortunately, one can then add 'statistical relevance' by determining the mathematical expression of the distance between two clustered groups in relation to their within-sample variance. Thus, the computed Mahalanobis' distance adds statistical weight to an already massaged series of data. The problems that this throws up for forensic presentation in court is beyond the scope of this paper and requires peer discussion before one can confidently go forward with such 'high level' interpretations.

The intricacies of the quartz grain type assemblage technique and its implications described in this paper do not detract from the fact that this is but one line of evidence. It would be foolhardy for any geoforensic technique to be the sole evidence in a case. The importance of the results from grain typing is in its association with other independent forensic

techniques such as environmental profiling [24][25] and other biological and sedimentological descriptive and exclusionary forensic techniques. 
The utilisation of quartz grain type assemblage percentages as an exploratory technique beyond that of using just grain type assemblages, is fraught with two primary assumptions. First, if a sample contained three quartz grain types, I, II and III, the provenance of that material could be from a nearby rock type which contained grain types I, II and III. Equally, the sample containing three quartz grain types, I, II and III, could comprise material from one source (type I and II) mixed before deposition to the present situation with material from another provenance (type III). The converse is also possible where type I grains mix before deposition with an alternative source containing types II and III grains. Finally, the sample containing types I, II and III grains could derive from three separate sources containing types I, type II and type III grains respectively which mix together before finally depositing at the sample site.

Second, using quartz grain type assemblage percentages from a sample, there is an implicit assumption that whatever the source of the materials, the variety of which is outlined above, the mixing ratios would have to be homogeneous within a sediment body and similar between samples of different provenances. Whilst this may apply to samples from very nearsource rock provenances, it would also require that the material derived from very discrete and homogeneous sedimentary layers. In part mitigation of this assumption, the scenario can exist where the diagenetic severity imparted upon a large area of sediment is uniform and the resultant diagenetic textures found on the quartz sand grains from the sample are therefore homogeneous throughout the sedimentary strata concerned [26].

By using quartz grain type assemblages it is possible to identify discrete sources of material which may for example, be found on a shoe. It would be possible to identify that three grain types (I, II and III) on the shoe were of the same assemblage as three grain types found from a comparator source area. Upon that shoe however, there may also be types IV and V, each taken from different sources of sediment. This technique can identify those different sources because there is no need to homogenise the sample prior to analysis as would be the case for chemical analysis by, for example, ICP analytical techniques. In this latter technique, the homogenised 'soup' which is analysed fails to identify different sources, but provides a meaningful exclusion of the material from the shoe with that of the comparator sediment source because it has integrated the chemical signatures of the other sources of material. Forensic analysis is more complicated than geological analysis because mixing of a sample is often an inevitable post-crime event and therefore, the geoscientific techniques selected for analysis must be chosen with great care.

\section{Conclusions}

The results from this study suggests a hitherto unrecognized identification of sediment-body en masse movement of materials, preserving not only spatial, but also temporal integrity of quartz grain type assemblages. Although quartz grain surface texture analysis is a very powerful reconstruction tool in geology, and an equally impressive descriptive tool in forensic science, it is the extension of these capabilities into quartz grain-typing which provides such a user-friendly and extremely powerful exclusion technique, specifically geared for forensic investigation. The potential importance of this technique can be found in the fact that quartz is the most common mineral on Earth. So, rather than concentrating on finding very low percentage, extremely exotic minerals, which may or may not provide effective comparison between samples, this technique seeks to analyse the most ubiquitous mineral found in a soil or sediment sample, thus enabling more meaningful and direct comparisons to be made between samples. Since comparatively few grains are required for analysis within a sample, the range of materials suitable to be analysed is large. Trace amounts of sand and soil are sufficient for meaningful analysis, thus adding to the potential forensic applicability of the technique.

The main conclusions from this study are:

- Quartz grain surface texture analysis, as employed for over 40 years for geological investigations, can be used to differentiate samples using a grain type assemblage technique.

- The number of quartz grain types identified from each sample during retrospective analysis of forensic materials are very low and provide a good database for exclusion techniques within the context of a forensic case.

- Grain type assemblages computed using ternary diagrams, provide good retrospective explanations normally compatible with other independent lines of forensic analysis. The use of these ternary associations may be adequate as simple descriptive materials but caution is urged if greater significance is required to be drawn from such associations.

- The order of classification of grain types which vary from 1st order (four types) to 5th order (80 types) provides an interesting and compelling foresight for computer automated pattern recognition.

- Quartz grain type assemblage analysis should be viewed as one technique of forensic analysis used in a case and is more powerful when compared with other independent techniques of forensic analysis.

\section{Acknowledgements}

The authors wish to thank Geoff Calvert, Chris White, Ailsa Allen, Mark Jackson, Dave Banfield and Chris Jackson from the School of Geography, University of Oxford for technical support. We would also like to thank Matt Morgan for his constructive comments of an earlier draft of this manuscript. Ruth Morgan acknowledges financial support from the Bruce, Julia and Mortimer May Senior Scholarship fund at Hertford College, Oxford. 


\section{References}

1 Nichols G 2001 Sedimentology and Stratigraphy. Blackwell Scientific Press. Oxford.

2 Culver SJ, Williams HR and Bull PA 1978 Infracambrian glaciogenic sediments from Sierra Leone. Nature, 274:49-51

3 Bull PA, Whalley WB and Magee AW 1985 An annotated bibliography of environmental reconstruction by SEM 1962-1985. British Geomorphological Research Group. Technical Bulletin No. 35. Geo Books. Norwich.

4 Smalley IJ 1974 Fragmentation of granitic quartz in water. Sedimentology 21:633-635

5 Ehlers J, Gibbard PL and Rose J (Eds) 1991 Glacial Deposits in Great Britain and Ireland. A. A. Balkema, Rotterdam.

6 Le Ribault L 1977 L'exoscopie des quartz. Paris: Masson

7 Krinsley DH and Doornkamp JC 1973 Atlas of Quartz Sand Surface Textures. Cambridge: Cambridge University Press.

8 Mahaney WC 2002 Atlas of Sand Grain Surface Textures and Applications. Oxford University Press, Oxford.

9 Bull PA 1981 Environmental reconstruction by electron microscopy. Progress in Physical Geography 6:368-397

10 Tovey NK and Wong KY 1978 Preparation, selection and interpretation problems in scanning electron microscope studies of sediments. In Whalley, W. B. (ed.) Scanning Electron Microscopy in the Study of Sediments. Norwich: geo Abstracts: 181-200

11 Vincent PJ 1976 Some periglacial deposits near Aberystwyth, Wales, as seen with a scanning electron microscope. Biuletyn Peryglacjalny 25:59-64

12 Krinsley DH and Margolis SV 1969 Study of the quartz sand grain surface textures with the SEM. Transactions of the New York Academy of Science 31 (5):457-477

13 Culver SJ, Bull PA, Campbell S, Shakesby RA and Whalley WB 1983 Environmental discrimination based on quartz grain surface textures: a statistical investigation. Sedimentology 30:129-136

14 Bull PA 2000 The Paviland Caves, Gower: The cave sediments. - In Aldhouse Green, S.(ed): Paviland Cave and the 'Red Lady'. A definitive report. Western Academic and Specialist Press Limited, Bristol, UK.

15 Goudie AS, Parker AG, Bull PA, White K and Al-Farraj A 2000 Desert Loess in Ras Al Kamaimah, United Arab Emirates. Journal of Arid Environments 46: 123-135.
16 Middleton NJ, Betzer PR and Bull PA 2001 Long-range transport of 'giant' aeolian quartz grains: linkage with discrete sedimentary sources and implications for protective particle transfer. Marine Geology 177: 441-417.

17 Morgan RM, Bull PA and Paskoff R 2005 Origin of the Cerro El Dragón coastal dune, Iquique, Atacama desert, Chile. Zeitschrift fur geomorphologie 49(2): 167182.

18 Davis JC 1973 Statistics and Data Analysis in Geology. John Wiley and Sons, Inc.

19 Higgs R 1982 Quartz-grain surface features of Mesozoic-Cenozoic sands from the Labrador and Western Greenland continental margins. Journal of Sedimentary Petrology 49 (2):599-61 0

20 Mazzullo J and Anderson J 1984 Grain shape and surface characteristics of basal till and glacial marine sands, Ross Ice Shelf: Fourier grain shape analysis. In Marshall, J. (ed) Characterisation and quantification of surface features on clastic and pyroclastic particles. New York. John Wiley and Sons.

21 Kirk PL 1974 Crime Investigation (2nd ed) Wiley Press, New York

22 Brunsden D and Thornes JB 1979 Landscape sensitivity and change, Transactions of the Institute of British Geographers 4: 463-484

23 Bull PA 2005 A scanning electron microscope study of sediments from the main cave sequence and new entrance sequence of Pontnewydd Cave. In AldhouseGreen, S. (ed) Pontnewydd and the Elwy Valley Caves. National Museum and Galleries of Wales. Cardiff. In Press.

24 Brown T 2000 Going to Ground. Police Review (4th February Edition) p18-20

25 Brown AG, Smith A and Elmhurst 02002 The combined use of pollen and soil analyses in a search and subsequent murder investigation. Journal of Forensic Sciences 47(3):61 4-618

26 Giles MR, Indrelid SL, Beynon GV and Amthor J 2000 The origin of large scale quartz cementation: evidence from large datasets and coupled heat-fluid mass transport modelling. In Worden, R. H, and Morad, S. (eds) Special Publication Number 29 Of The International Association of Sedimentologists. 21-38 